\title{
Effects of mooring management on submerged vegetation, sediments and macro-invertebrates in Lake Constance, Germany
}

\author{
Wolfgang Ostendorp · Thomas Gretler • \\ Martin Mainberger · Markus Peintinger • \\ Klaus Schmieder
}

\begin{abstract}
Mooring areas are a common form of berthing in many of Germany's inland waters for the growing number of sporting boats. A circular swinging zone around the anchor zone is formed, in which the submerged macrophyte vegetation is destroyed to a large extent, and the sediment surface is eroded. We investigated the effects of two types of buoy (conventional and so-called hook-buoys) in comparison with undisturbed reference sites nearby. The aim of the study was to identify possible harmful consequences of mooring sites to lake littoral habitats in Lake Constance-Untersee, and to provide information
\end{abstract}

to managers to aid them in the formulation of mooring management plans with the least ecological impact. The study focused on submerged vegetation, surface sediments and macro-invertebrate colonisation. In the swinging circle of conventional buoys $\left(87 \mathrm{~m}^{2}\right)$ we observed a significant sediment matter erosion of 0.9 tonnes and a reduction of organic matter amount by $4.5 \%$ of the undisturbed reference. The vegetation free area increased by $122 \%$, and the phytomass (mainly Chara div. spp.) was reduced by $14.6 \%$ per berth. The psammophilous macro-invertebrate numbers were not significantly affected $(-3 \%)$ in contrast to the phytophilous taxa which were reduced by $12.7 \%$ per berth. The mayfly larvae were the most negatively affected taxon. Oligochaetes profited from the clearing of the sediment surface in the swinging circles. The ecological effects of the hook-buoys were more minor, mainly due to the smaller swinging circle $\left(6 \mathrm{~m}^{2}\right)$. We concluded that the detrimental effects of mooring can be significantly reduced by mooring systems, e. g. the hookbuoy system as it was used in this study, which reduce the area disturbed and cleared by the anchor chain. We argue that these results can be generalised to mooring areas with soft bottom and dense macrophyte vegetation in Lake Constance and other large lakes. 


\section{Introduction}

Mooring areas are a common form of berthing in many of Germany's inland waters for the growing numbers of sporting boats. They are cheap in comparison to harbours, jetties or landing stages and simple to install, as they only consist of an anchor stone, a heavy anchor chain and a buoy per berth. With a fluctuating water level and changing wind, the anchor chain is not normally taut but rather drags along the ground according to the strength and direction of the relevant forces. A circular swinging zone around the anchor zone is therefore formed, in which the submerged macrophyte vegetation is destroyed to a large extent, and the sediment surface is exposed (Fig. 1).

Damage to submerged vegetation and associated fauna by mooring activities has been frequently reported from marine shores (Walker et al. 1989; Lenihan et al. 1990; Creed and Amado Filho 1999; Francour et al. 1999; Marba et al. 2002; Milazzo et al. 2004). Seagrass beds are particularly vulnerable. Only a few reports exist from inland waterways (e.g. Wade 1999). Here, Phragmites australis beds and floating water plant vegetation suffer from moorings.

The degree of damage depends on anchoring practices and anchor types, as well as on exposure to prevailing swell (Hastings et al. 1995; Milazzo et al. 2004). Most observations refer to 'free' anchoring at arbitrarily selected places near the coast. In such cases the physical damage of anchoring arises from anchor fall, dragging and locking in the anchor, and from weighing downwind. The effect of 'fixed' moorings, e.g. buoys at anchor held in position by anchor weights as is the case in Lake Constance, has not been investigated yet, though this mooring type is frequently used for small vessels in sheltered marine bays and in lakes (Fig. 1b).

The possibility of using different types of buoys and anchoring devices is currently under discussion, as a further step aimed at reducing the ecological effects of the buoy fields (BiCon, unpublished report). There is a range of possible technical solutions, of which the so-called hook-buoys have proven to be the best at Lake Constance in terms of operating reliability, costs and practicability. Here the anchor chain is manually shortened or lengthened by a carabiner clasp according to the level of water present, so that only a small section of the anchor chain drags along the ground (Fig. 1c).

In July 2005 we conducted a comparative survey of the ecological effects of the conventional buoys and the hook-buoy system in a buoy field in Lake Constance-Untersee. The aim of the study was to analyse the direct effects of the two mooring practices on submerged vegetation, surface sediments and macro-invertebrate colonization by comparison with associated undisturbed reference sites nearby.
Fig 1 a Buoy field of Gundholzen in 2003 before the hook-buoy system was established in its eastern part, showing the swinging circles of conventional moorings (source: State Land Surveying Office Baden-Wuerttemberg), b conventional mooring, c hook-buoy mooring with a tout anchor chain and a narrow swinging circle
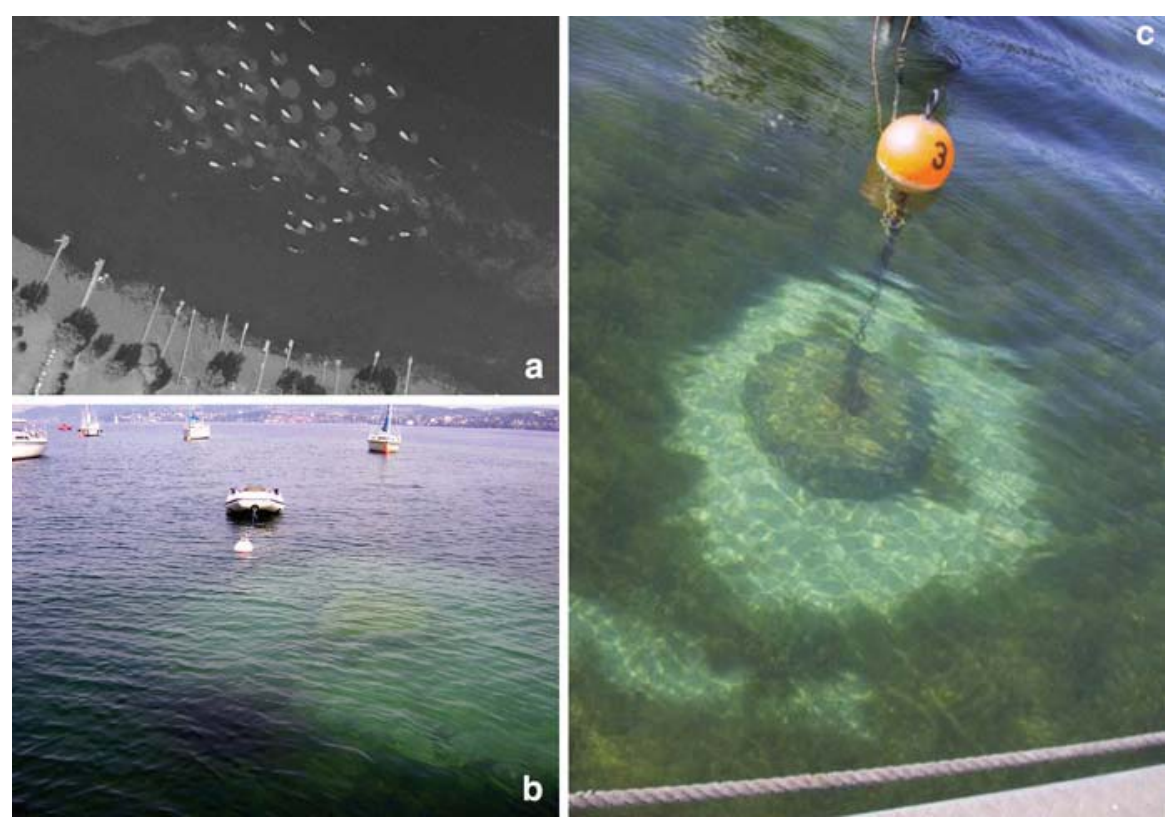
The field data was used to compute four scenarios to serve as guidance for waterways authorities and managers in the formulation of future mooring management plans with the least ecological impact.

\section{Site description}

Lake Constance has a surface area of $529 \mathrm{~km}^{2}$ and has a maximum depth of $253 \mathrm{~m}$, making it the largest northern prealpine lake. The seasonal course of the lake level is mainly determined by the alpine catchment, i.e. the lake level declines in winter, when precipitation in the catchment is to a large extent stored as snow and reaches its maximum level in June/July due to increased precipitation and snowmelt. Lake Constance-Untersee $\left(61 \mathrm{~km}^{2}\right.$, max. depth $40 \mathrm{~m}$ ), the lower basin of Lake Constance is a eutrophic lake with wide shelves covered with lake marl and vegetated with extended Chara spp., and Potamogeton spp. meadows.

At present on Lake Constance, about 2,646 boats, i.e. about $12 \%$ of all berths, are moored in 44 mooring fields and in 31 single buoy groups (IGKB 2005) covering an area of c. $1.5 \mathrm{~km}^{2}$. On the German shores of the Lake many of the mooring fields are located in NATURA 2000 nature reserves (habitat type 3140, "Hard oligo-mesotrophic waters with benthic vegetation of Chara spp."), which are protected under the European Habitats Directive (Directive 92/43/EEC, Annex 1) which also prohibits the deterioration of their condition.

The surveyed buoy field of Gundholzen is on the south-western shore of Lake Constance-Untersee

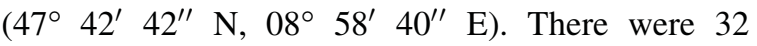
sailing boats and motor boats using conventional buoy berths and 22 boats using hook-buoy berths (Fig. 1a). The buoy field is protected from the prevailing west and south-western winds by a hill ridge. Winds from other directions reach the shore over the open lake surface (Bäuerle et al. 1998). The buoys are between approx. 80-200 $\mathrm{m}$ away from a near-natural section of the bank, $0.85-1.65 \mathrm{~m}$ deep under the mean annual water level (mwl 1951-2004: $395.08 \mathrm{~m}$ a.s.l. Amsterdam, water gauge Berlingen). They are between 1.95 and $2.75 \mathrm{~m}$ deep under the mean high water level (mhwl $396.18 \mathrm{~m}$ a.s.1.) which usually occurs between the end of June until the beginning of July. However, at the time of sampling (15th-16th July 2005) the positions were only in a depth of $0.9-1.7 \mathrm{~m}$ of water, due to a seasonally unusual low water level in 2005. In the western sector of the buoy field, conventional anchor buoys were used and in the eastern sector hook-buoys were used where the anchor chain length was adjusted weekly by the municipal manager according to the water level at that time. In general, the boats are launched and moored to the anchor stones during May, and removed from the lake and parked on land mooring areas by the end of September. The buoys and the chains are also removed but the anchor stones (often made of car tyres, c. $0.6-1.0 \mathrm{~m}$ in diameter, filled with gravel concrete) remain in place.

\section{Sampling plan, methods, and scenarios}

In the Gundholzen buoy field twelve buoy moorings were selected, each consisting of a disturbed area (swinging circle) and an unaffected area (reference) within a perimeter of c. 3-5 m outside the swinging circle (Fig. 2). Six pairs were conventional buoy moorings and six were hook-buoy moorings. The positions of the buoy types were prearranged by the municipial managers of the mooring area; the sampling plot in each swinging circle and reference area was randomly selected. Sampling took place during the season of peak phytomass when the boats had been moored for about 2 months.

The surveyed parameters and laboratory analyses included the size of each swinging circle, the submerged macrophyte vegetation (coverage, species composition, phytomass [only in reference areas]), surface sediments (grain size distribution, ash-free organic matter $[\mathrm{OM}]$, total carbonate $\left[\mathrm{C}_{\mathrm{inorg}}\right]$, total phosphorus $\left[\mathrm{P}_{\mathrm{t}}\right]$ ) and the macro-invertebrate fauna of (i) the sediments and of (ii) the macrophytes. The underwater work was carried out by scientific divers.

The percentage coverage of submerged macrophytes was visually estimated by trained scientific divers. The nomenclature follows Krause (1997) and Buttler and Harms (1998). The phytomass samples, which also served for the collection of the macroinvertebrate epifauna, were taken from a $0.30 \mathrm{~m} \times$ $0.30 \mathrm{~m}$ area of the lake bed with a stainless steel cutting frame and were directly placed into polyethylene bags in order to avoid the loss of mobile animals. The samples were cleaned and sieved within a day in 
Fig 2 Schematic view of a conventional mooring site, plan view and cross-section; A-position of the boat during a gentle breeze from the east, B-during a stiff breeze from the south-west (examples, see text for further details)

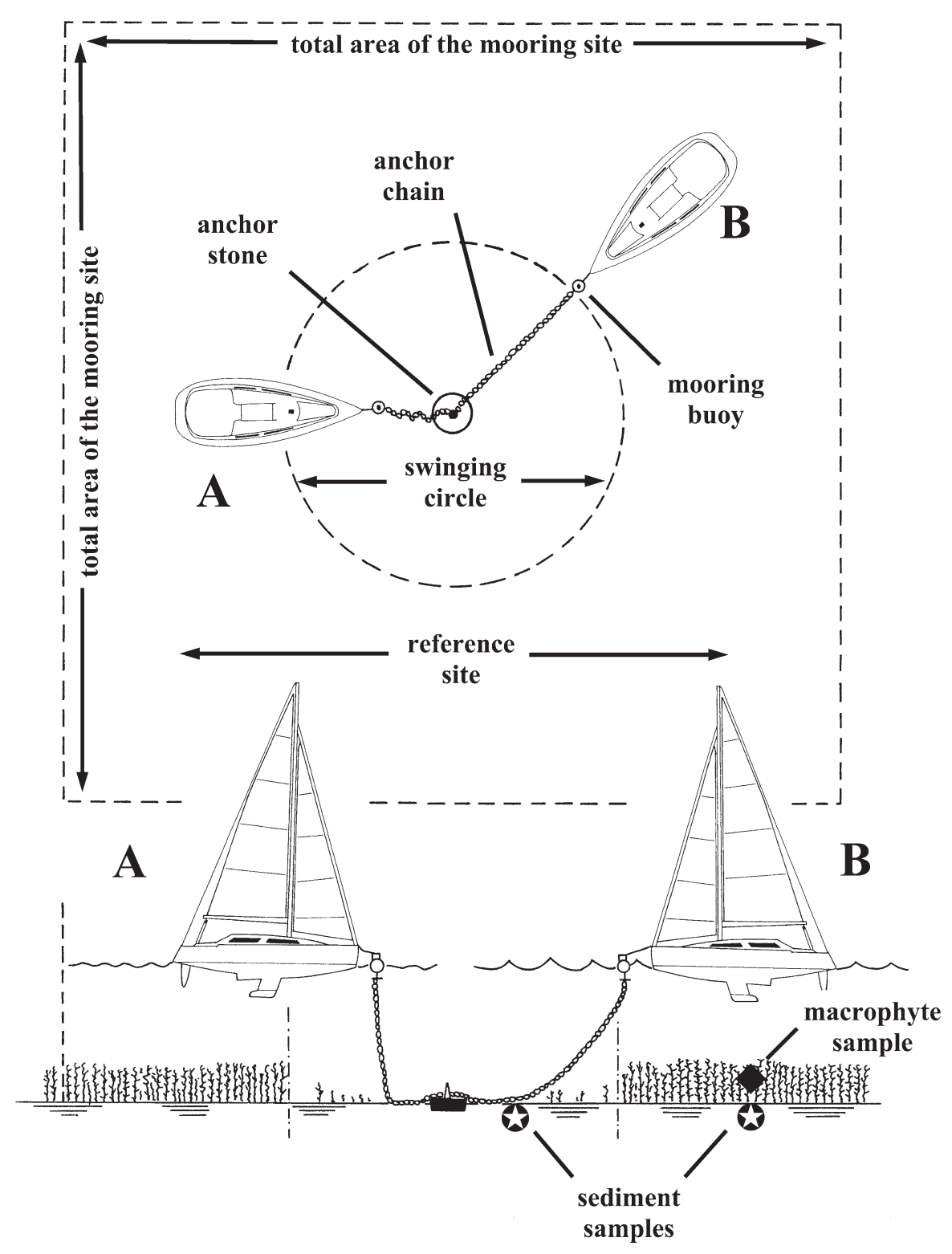

a sieve set with mesh sizes of 1.0 and $0.2 \mathrm{~mm}$. The two residuals consisted of some small plant pieces and the living macro-invertebrate animals. This material was then processed as described below. The remaining phytomass, after taking a subsample from it, was dried $\left(75^{\circ} \mathrm{C}, 72 \mathrm{~h}\right)$ in order to determine the dry matter (d.m.).

Different processes were used to obtain the fraction of larger animals $(>1.0 \mathrm{~mm})$ and smaller animals $(0.2-1.0 \mathrm{~mm})$ on and within the sediments. To obtain the larger animals a specially-made dredge (mesh size $1.0 \mathrm{~mm}$ ), opening size $20 \times 10 \mathrm{~cm}$ ) was dragged by hand in a depth of $3 \mathrm{~cm}$ through the surface sediments. A surface area of $0.144-0.288 \mathrm{~m}^{2}$ in a sediment depth of $3 \mathrm{~cm}$ was removed. In order to carry out sediment sampling in the macrophyte stands, an area of approx. $0.3 \mathrm{~m}^{2}$ at three locations was cut free and the plant material was removed from it before the sediment samples were taken. The sediment material was immediately sieved $(1 \mathrm{~mm}$ mesh size) on board the boat, the remainder with the still living benthos animals, was cleaned, counted, classified and fixed in iso-propanol (70\% v/v with $1 \%$ glycerine). Leeches (Hirudinea) were classified alive. 
To obtain the fraction of smaller animals two polyethylene basins with a diameter of $9.8 \mathrm{~cm}$ and $3.7 \mathrm{~cm}$ height were pushed into the sediment and secured together with the sediment core. After taking samples to estimate water content, distribution of grain size and the content of carbonate and total phosphorus, the remaining sediment was sieved $(0.2 \mathrm{~mm}$ mesh size). The residue fraction $(0.2-$ $1.0 \mathrm{~mm}$ ) which included the inorganic sediment, plant debris and living animals was fixed for later enumeration.

The quantitative counting of the macro-invertebrate individuals took place on the basis of families and orders of arthropods and sub-classes and classes of other invertebrates. Genus and species classifications were undertaken for individual taxa. The animals within the entire sample (fraction of larger animals) and in a homogeneous subsample (smaller animals) were counted to approx. 100-500 individuals and this number was projected onto the colonisation density of a $1 \mathrm{~m}^{2}$ littoral area (Z). The densities were normalised using the $\log _{10}(Z+1)$ transformation $\left(\mathrm{pZ}_{\mathrm{i}}\right)$ (see Armitage et al. 1995) before the statistical evaluations were carried out.

The content of the organic matter in the sediments and the ash content of the phytomass samples were measured by ignition loss $\left(8 \mathrm{~h}, 560^{\circ} \mathrm{C}\right)$. The ash was used to determine total phosphorus after digestion with conc. $\mathrm{H}_{2} \mathrm{SO}_{4}\left(4 \mathrm{~h}, 175^{\circ} \mathrm{C}\right)$ and the addition of $\mathrm{H}_{2} \mathrm{O}_{2}\left(2 \mathrm{~h}, 110^{\circ} \mathrm{C}\right)$. An aliquot was taken from the supernatant, neutralised and analysed for reactive $\mathrm{P}$ using the molybdenum blue reaction. The carbonate content was analysed in the organic matter free residue. About $60 \mathrm{mg}$ were dissoluted in $2 \mathrm{ml}$ of $2 \mathrm{~mol} 1^{-1} \mathrm{HCl}$ during $30 \mathrm{~min}$ in $60^{\circ} \mathrm{C}$. The remaining acid was titrated with $0.1 \mathrm{~mol} \mathrm{l}^{-1} \mathrm{NaOH}$. The carbonate was equivalent to the amount of $\mathrm{HCl}$ used.

The grain size distribution of the surficial sediment layers $(0-3 \mathrm{~cm})$ was measured with the Saturn DigiSizer ${ }^{\circledR} 5200$ of Micromeritics ${ }^{\circledR}$. About $2 \mathrm{~g}$ of the fresh sediments were sieved $(0.63 \mathrm{~mm})$, the coarser fraction was discarded, and the finer fraction was disaggregated with $10 \% \mathrm{v} / \mathrm{v} \mathrm{H}_{2} \mathrm{O}_{2}$ for 2 weeks, homogenized with ultrasonics and analysed according to the standard laboratory protocols. The output from the fitted distribution curve was re-calculated to give 11 grain size classes (from $<2 \mu \mathrm{m}$ - clay to $355-$ $630 \mu \mathrm{m}$ - coarse medium sand) according to the ISO 3310-1 scale.
$\mathrm{OM}, \mathrm{P}_{\mathrm{t}}$, and $\mathrm{C}_{\text {inorg }}$ are given as 'content' $\left(\mathrm{mg} \mathrm{g}^{-1}\right.$ d.m., mmol $\mathrm{g}^{-1}$ d.m.) as well as 'amount' $\left(\mathrm{g} \mathrm{m}^{-2}\right)$ in the upper sediment layer of 0-3 cm depth. 'Amounts' were computed by multiplying the 'contents' with the bulk density ( $\mathrm{g}$ d.m. $\mathrm{cm}^{-3}$ ) of the associated sediment sample.

The effect of mooring was analysed by the pairwise comparison of swinging circle plots and reference plots (paired $t$-test, or Wilcoxon matched pairs signed rank test in the case of unequal variances, $n=12$ pairs). The differential effect of the new hook-buoy system compared with the conventional buoy system was analysed by comparison of the mean differences between swinging circle and reference plots using an unpaired $t$-test or a Wilcoxon median test. Data is given as means \pm SD.

To quantify the effects of (i) the conventional mooring system, and (ii) the hook-buoy system, the following scenarios were developed (see Fig. 2 for illustration):

A-mean area $\left(\mathrm{m}^{2}\right)$ needed for one boat moored at a conventional buoy (index conv) or a hook buoy (index hook)

$\mathrm{B}$-mean area $\left(\mathrm{m}^{2}\right)$ of the swinging circle of a conventional buoy (index conv) or a hook buoy (index ${ }_{\text {hook}}$ )

$\mathrm{N}$-total number of macro-invertebrate individuals (ind.) in the macrophyte layer and in the top sediment layer $(0-3 \mathrm{~cm})$

$\mathrm{Z}$-density of macro-invertebrates (ind. $\mathrm{m}^{-2}$ ) in the macrophyte layer (index macr), the top sediment layer (index ${ }_{\text {sed }}$ ) or in both (index total)

$\mathrm{D}$-coverage (\% ground area) of the macrophyte layer

- Scenario 1: no boat is moored at one potential berth site. The area of $A_{\text {conv }}, A_{\text {hook }}$ is left in its natural state. The features of this area were estimated from the site characteristics of the corresponding reference site $(n=12)$ multiplied by the reference area size. Example calculation for the total number of macro-invertebrates in $\mathrm{A}_{\text {conv }}: \mathrm{N}$ [ind.] $=\mathrm{A}_{\text {conv }} \times\left(\mathrm{Z}_{\text {sed,ref }}+\mathrm{Z}_{\text {macr,ref }}\right)$

- Scenario 2: one boat is moored at one berth site (area $\mathrm{A}_{\text {conv }}$ ) using a conventional buoy. The characteristics of the area were estimated from the site characteristics of the swinging circle $(n=6)$ and 
the surrounding areas, which are then equated with the corresponding reference areas $(n=6)$, multiplied with the area size of the swinging circles or the remaining area. As the phytomass in the swinging circles had not been measured separately, it was estimated from the proportionality between the degree of coverage and phytomass in the other sites. Example calculation for the total number of macroinvertebrates in $\mathrm{A}_{\text {conv }}$ : $\mathrm{N}$ [ind.] $=\left(\mathrm{A}_{\text {conv }}-\right.$ $\left.\mathrm{B}_{\text {conv }}\right) \times\left(\mathrm{Z}_{\text {sed,conv,ref }}+\mathrm{Z}_{\text {macr,conv,ref }}\right)+\mathrm{B}_{\text {conv }} \times$ $\left(\mathrm{Z}_{\text {sed,conv,swing }}+\mathrm{D}_{\text {swing,conv }} / 100 \times \mathrm{Z}_{\text {macr,conv,ref }}\right)$

- Scenario 3: one boat is moored at one berth site (area $\mathrm{A}_{\text {conv }}$ ) using a hook-buoy; the calculation is essentially the same as that in scenario 2 , so that the total number of macro-invertebrates in $\mathrm{A}_{\text {conv }}$ is $\mathrm{N}$ [ind.] $=\left(\mathrm{A}_{\text {conv }}-\mathrm{B}_{\text {hook }}\right) \times\left(\mathrm{Z}_{\text {sed,hook,ref }}+\right.$ $\left.Z_{\text {macr,hook,ref }}\right)+B_{\text {hook }} \times\left(Z_{\text {sed,hook,swing }}+D_{\text {swing, }}\right.$, hook $/ 100 \times \mathrm{Z}_{\text {macr,hook,ref }}$ )

In scenario 3 the number of boats in the buoy field is the same as in scenario 2. However, in the transition from conventional buoys to hook-buoys about $33 \%$ of the mooring area is spared because the anchor chain is shorter and the swinging circle of the boats is smaller $\left(\mathrm{A}_{\text {conv }}=1.5 \times \mathrm{A}_{\text {hook }}\right)$. One can imagine that the area which becomes free due to the changeover to hook-buoys will be filled with more hook-buoys and more boats, e.g. when the total area of the buoy field considered is diminished, or when other buoy fields are suspended (scenario 4). This would be the scenario favoured according to current legal and administrative practices. In this case 1.5 boats could be moored in a mooring area of $\mathrm{A}_{\text {conv }}$ under the conditions of the Gundholzen mooring site:

- Scenario 4: 1.5 boats are moored on 1.5 hookbuoys in an area of $\mathrm{A}_{\text {conv }}$; the method of calculation is similar to scenario 3 , except $B_{\text {hook }}$ is multiplied by a factor of 1.5 , whereby the remaining undisturbed area also becomes correspondingly smaller: $\mathrm{N} \quad$ [ind. $]=\left(\mathrm{A}_{\text {conv }}-\right.$ $\left.1.5 \times \mathrm{B}_{\text {hook }}\right) \times\left(\mathrm{Z}_{\text {sed,hook,ref }}+\mathrm{Z}_{\text {macr,hook,ref }}\right)+$ $1.5 \times \mathrm{B}_{\text {hook }} \times\left(\mathrm{Z}_{\text {sed,hook,swing }}+\mathrm{D}_{\text {swing,hook }} / 100 \times\right.$ $\mathrm{Z}_{\text {macr,hook,ref) }}$

Using these scenarios the following practical questions of managers can be answered:

- What does a completely unaffected area look like (scenario 1)?
- What will happen, when a formerly idle shore section is used as a berth site with the conventional mooring system (comparison of scenario 2 with scenario 1$)$ ?

- What will happen, when a mooring site, formerly conventionally used, is equipped with a hook buoy (comparison of scenario 3 with scenario 2)?

- What will happen, when the boat density per berth is increased, using the hook buoy system (comparison of scenario 4 with scenario 3 )?

\section{Results}

Effect of the water depth

The swinging circle areas of both mooring systems were at the same depth as the associated reference sites. The mean water depths of the conventional moorings $(1.37 \pm 0.08 \mathrm{~m})$ and those of the hookbuoy moorings $(1.24 \pm 0.30 \mathrm{~m})$ were not significantly different from each other. The water depth of the moorings did not have a significant effect on the percentage cover of macrophytes, the plant biomass, the total carbonate, the organic matter, the grain size median and the total macro-invertebrate density, and it is therefore disregarded as a covariable. Only the $\mathrm{P}_{\mathrm{t}}$ content and the $\mathrm{P}_{\mathrm{t}}$ amount in the upper sediment layers decreased significantly with higher water depth ( $r=0.573, P<0.01$ for the $\mathrm{P}_{\mathrm{t}}$ content, $r=0.467$, $P<0.05$ for the $\mathrm{P}_{\mathrm{t}}$ amount, $n=24$ sampling sites, Pearson correlation).

Size of the swinging circles and the percentage cover of macrophytes

The average space required by a boat for the conventional moorings in the Gundholzen buoy field is $580 \mathrm{~m}^{2}$, and $387 \mathrm{~m}^{2}$ for moorings on hook-buoys. The disturbance zone of the swinging circles of the conventional buoy type was significantly larger than the swinging circle of the hook-buoys $\left(87 \pm 40 \mathrm{~m}^{2}\right.$ vs. $6 \pm 5 \mathrm{~m}^{2}, P<0.01, \mathrm{n}_{1}=\mathrm{n}_{2}=6$, Wilcoxon median test). In the latter, the destruction area consisted of the anchor stone of the mooring and a circular disturbance zone of approx. $1 \mathrm{~m}$ width (Fig. 1c). 
The underwater vegetation consisted mainly of stoneworts, above all Chara aspera (Dethard) Willd., Ch. contraria Kützing, and Nitella obtusa (Desvaux) J.Grooves, as well as Najas intermedia Wolfg. and Potamogeton pectinatus L. The two named Chara species accounted for more than $80 \%$ of the vegetation canopy in the reference sites. In some areas $P$. panormitanus Biv.-Bern. and Zannichellia palustris $\mathrm{L}$. were also found. The species spectrum of the swinging circles and the reference sites did not differ greatly from one another; however Ch. tomentosa L. was found almost exclusively in reference areas. The mean species number was significantly lower in the swinging circles (3.7 species per berth) than in the related reference sites ( 4.8 species; Table 1$)$. The type of buoy had no significant influence on the numbers of species in either the swinging circle or the neighbouring reference site.

The mean macrophyte vegetation cover was significantly lower in the swinging circles than in the reference sites (10 and 91\%). In the swinging circles of both mooring systems the vegetation cover was approx. 1 to $2 \%$ except for two of the six hook-buoys where the cover was $40-50 \%$. In one of these cases the boat was on the lake at the time of field work.

\section{Sediments}

The surface sediments consisted of a fine to medium grained lake marl matrix with a patchy overlay of pebbles (normally $<1 \%$ coverage, up to $50 \%$ in the swinging circle of some landward hook buoy moorings). Pebbles were discarded in the sediment analyses.

The swinging circle sediments, compared with the reference sediments, had a significantly higher bulk density, lower organic matter content, lower $C_{\text {inorg }}$ content, and lower organic matter amount in the top sediment layer (Table 1 ). The mean $\mathrm{P}_{\mathrm{t}}$ content and the mean $\mathrm{C}_{\text {inorg }}$ amount were also lower but the difference was not significant. The buoy type had no significant influence on the means of pairwise differences of any of these variables between reference and swinging circle sites.

The mean grain size distribution of sediments in the swinging circles and in the reference zones was similar (Fig. 3), with a modal grain size in the finer medium sand $(200-355 \mu \mathrm{m})$ fraction. The percentages of finer grain size classes (from clay $[<2 \mu \mathrm{m}]$ to finer fine sand [63-112 mm]) were significantly higher in the reference site sediments whereas the percentages of finer and coarser medium sand (200$355 \mu \mathrm{m}$ and $355-630 \mu \mathrm{m}$ ) were significantly lower $(P<0.01$ in most cases, $n=12$ Wilcoxon matched pairs signed rank test). No significant difference was found for the coarser fine sand fraction (112$200 \mu \mathrm{m})$. The buoy type had no significant influence on the means of pairwise differences of grain size percentages between reference and swinging circle sites for most grain size classes, except for the coarser

Table 1 Comparison of macrophyte vegetation and sediment properties in the swinging circle and the reference area (treatment effect)

\begin{tabular}{|c|c|c|c|}
\hline & \multicolumn{3}{|l|}{ Treatment effect } \\
\hline & Swinging circle & Reference site & Significance \\
\hline Macrophytes: species number per berth (1) & $3.7 \pm 0.9$ & $4.8 \pm 1.0$ & $*$ \\
\hline Macrophytes: coverage (\%) & $10 \pm 17$ & $91 \pm 4$ & $* * * *$ \\
\hline Macrophytes: phytomass (kg d.m. $\mathrm{m}^{-2}$ ) & n.d. & $0.155 \pm 0.049$ & - \\
\hline Sediment: bulk density (g d.m. $\mathrm{cm}^{-3}$ ) & $0.96 \pm 0.10$ & $0.72 \pm 0.15$ & $* *$ \\
\hline Sediment: OM content ( $\mathrm{mg} \mathrm{g}^{-1}$ d.m.) & $11 \pm 4$ & $20 \pm 6$ & $* * * *$ \\
\hline Sediment: OM amount $\left(\mathrm{g} \mathrm{m}^{-2}\right)$ & $315 \pm 113$ & $417 \pm 79$ & $* *$ \\
\hline Sediment: $\mathrm{P}_{\mathrm{t}}$ content $\left(\mathrm{mg} \mathrm{g}^{-1}\right.$ d.m.) & $0.172 \pm 0.032$ & $0.193 \pm 0.039$ & n.s. \\
\hline Sediment: $\mathrm{P}_{\mathrm{t}}$ amount $\left(\mathrm{g} \mathrm{m}^{-2}\right)$ & $5.04 \pm 0.86$ & $4.10 \pm 1.37$ & n.s. \\
\hline Sediment: $\mathrm{C}_{\text {inorg }}$ content $\left(\mathrm{mmol} \mathrm{g}^{-1} \mathrm{~d} . \mathrm{m}.\right)$ & $2.66 \pm 0.70$ & $4.31 \pm 1.42$ & $* * * *$ \\
\hline Sediment: $\mathrm{C}_{\text {inorg }}$ content $\left(\mathrm{mol} \mathrm{m}^{-2}\right)$ & $77 \pm 16$ & $86 \pm 10$ & n.s. \\
\hline
\end{tabular}

Means $\pm \mathrm{SD}$; paired $t$-test, or Wilcoxon matched pairs signed rank test in the case of unequal variances, $n=12$ pairs; n.s. -not significant for $P>0.05$, * $P<0.05$, ** $P<0.01$, *** $P<0.001$, **** $P<0.0001$, n.d. - not determined. Data from conventional and hook-buoy moorings was pooled since buoy type had no significant effect on either of these variables 
Fig 3 Mean grain size distributions of surface sediments $(0-3 \mathrm{~cm})$ in the swinging circles and in the reference sites (means $\pm \mathrm{SD}$ ), ** $P<0.01, * P<0.05$

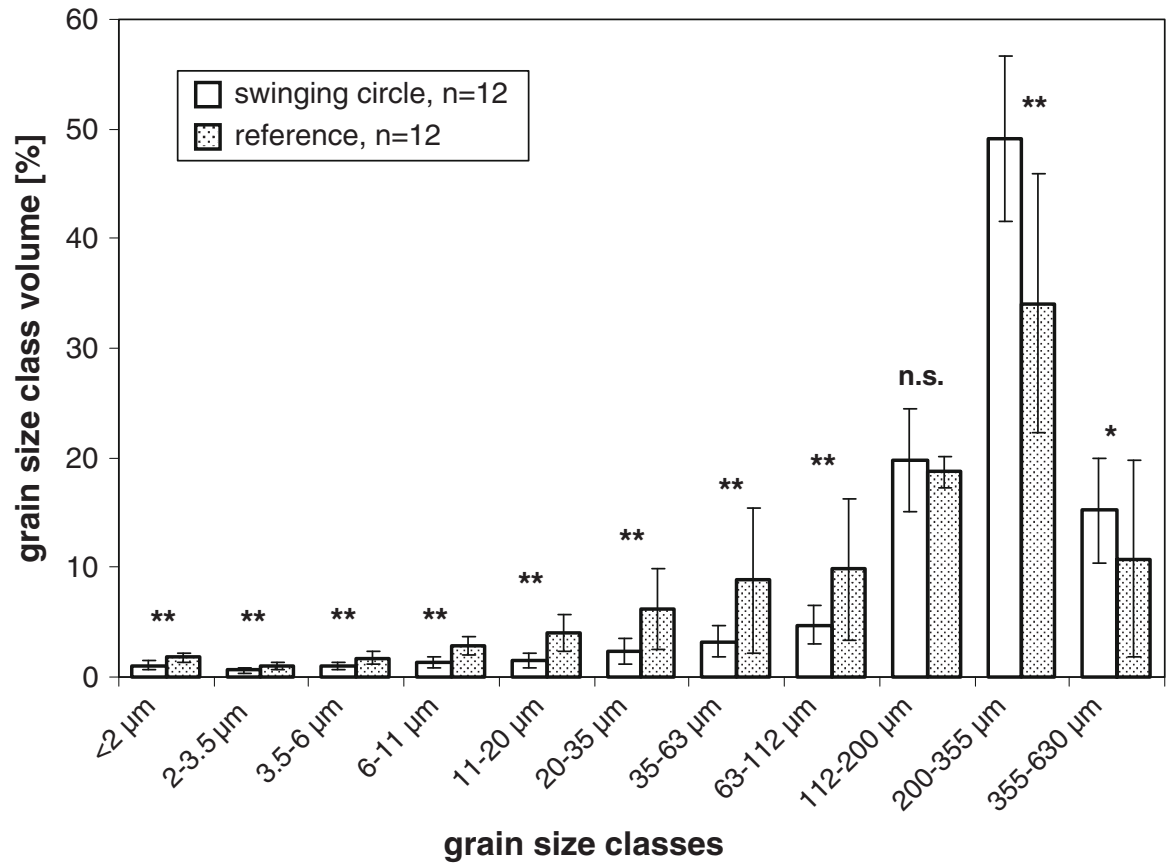

fine sand. Here, the reference sites of hook-buoys had significantly higher percentages in this grain size class than the conventional buoys $(21 \pm 6 \%$ vs. $16 \pm 4 \%, P<0.05$, Wilcoxon median test, $\mathrm{n}_{1}=$ $\mathrm{n}_{2}=6$ ), but the swinging circle sediments did not differ significantly (19 $\pm 3 \%$ conventional, $21 \pm 6 \%$ hook-buoys).

Assuming that the coarsening of the swinging circle sediments was due to the erosion of fine particles from clay to fine sand size classes (see Discussion), and assuming that the medium sand fraction remained in place, a rough estimate of eroded sediment matter is possible based on the two grain size histograms: on average about $27 \%$ of the total sediment matter ( $0-3 \mathrm{~cm}$ depth) has to been moved away from the swinging circle, to transform the shape of the grain size histogram of reference sediments into that of the swinging circle sediments. This estimate does not account for the possibility that some eroded particles of the swinging circle sediments may have settled down in the immediate surroundings, i.e. in the reference sites. We assume that this effect can be neglected since the reference area is about 5 times greater than the swinging circle area.

The OM, $\mathrm{P}_{\mathrm{t}}$, and carbonate concentrations were significantly positively correlated with the percentage of particles $<0.112 \mathrm{~mm}$ (OM: $r=0.840, \mathrm{CO}_{3}{ }^{2-}$ : $\mathrm{r}=0.975, \quad P<0.001 ; \quad \mathrm{P}_{\mathrm{t}}: \quad r=0.492, \quad P<0.05 ;$ $n=24)$. Hence, the variation in chemical properties can partly be explained by the coarsening of the sediment by erosion processes.

Total density of macro-invertebrate individuals

The total densities [ind. $\mathrm{m}^{-2}$ ] of the macro-invertebrates were estimated (i) in the upper sediment layer of the disturbance zone of both mooring types, (ii) in the macrophyte stands of the reference sites, and (iii) in the upper sediment layer of the reference sites, after removal of the macrophytes.

The transformed mean density $\left(\mathrm{pZ}_{\text {total }}\right)$ was $4.69 \pm 0.23$ in the sediments of the swinging circles ( $n=12), 4.69 \pm 0.19$ in the sediments of reference sites $(n=12)$ and $4.69 \pm 0.22$ in the macrophyte stands $(n=12)$ of the reference sites. This corresponds to densities of 48,980, 48,860 and 48,750 individuals per square meter (Table 2). The means were not significantly different from one another. The mean density in swinging circle sediments of the conventional buoy moorings was 58,960 ind. $\mathrm{m}^{-2}$ $\left(\mathrm{pZ}_{\text {total }}=4.77 \pm 0.22\right)$, whereas in the swinging circle sediments of the hook-buoy moorings the density was lower with 40,680 ind. $\mathrm{m}^{-2}$ (pZ $\mathrm{p}_{\text {total }}=$ $4.61 \pm 0.24)$. Both groups had an outlier $(23,440$ and 120,230 ind. $\mathrm{m}^{-2}$ ). If these values were excluded 
Table 2 Comparison of macro-invertebrate colonisation of macrophyte stands $(n=12)$ and sediments $(n=24)$ (habitat effect) as well as the swinging circle sediments $(n=12)$ and the reference area sediments $(n=12)$ (treatment effect)

\begin{tabular}{|c|c|c|c|c|c|c|c|}
\hline \multirow[t]{2}{*}{ Taxon } & \multirow[t]{2}{*}{ Frequency $(\%)$} & \multicolumn{3}{|l|}{ Habitat effect } & \multicolumn{3}{|c|}{ Treatment effect (sediments) } \\
\hline & & Macrophytes & Sediment & Sign. & Swinging circle & Reference site & Sign. \\
\hline Bivalvia & 97 & & & & $2.30 \pm 2.05$ & $4.19 \pm 0.30$ & $(*)$ \\
\hline Chironomidae & 100 & $3.48 \pm 0.17$ & $3.81 \pm 0.35$ & $* *$ & & & \\
\hline Ephemeroptera & 92 & $4.14 \pm 0.34$ & $2.06 \pm 1.13$ & $* * * *$ & & & \\
\hline Oligochaeta & 89 & $1.61 \pm 1.07$ & $3.07 \pm 1.06$ & $* *$ & & & \\
\hline Gastropoda & 89 & $3.05 \pm 0.54$ & $1.86 \pm 1.11$ & $* *$ & $1.81 \pm 1.46$ & $2.46 \pm 0.76$ & $* * * *$ \\
\hline Hirudinea & 100 & & & & $1.66 \pm 0.95$ & $2.66 \pm 0.88$ & $* *$ \\
\hline Trichoptera & 100 & $2.68 \pm 0.49$ & $1.74 \pm 0.40$ & $* * * *$ & & & \\
\hline Isopoda & 64 & $2.02 \pm 1.07$ & $0.91 \pm 1.01$ & ** & $0.46 \pm 0.57$ & $1.53 \pm 0.98$ & $* *$ \\
\hline Hydrozoa & 58 & $2.53 \pm 0.44$ & $0.40 \pm 0.55$ & $* * * *$ & & & \\
\hline Total & 100 & $4.69 \pm 0.22$ & $4.69 \pm 0.21$ & n.s. & $4.69 \pm 0.23$ & $4.69 \pm 0.19$ & n.s. \\
\hline
\end{tabular}

Frequency of the taxa (in \% of all samples, $n=36$ ), means \pm SD of the $\log _{10}(\mathrm{Z}+1)$ transformed densities (individuals $\mathrm{m}^{-2}$ ) $\mathrm{pZ}_{\mathrm{i}}$, as well as the significance of the Wilcoxon matched pairs signed rank test are all specified. Only taxa for which significant effects were found are displayed

For symbols see Table 1

from the calculations, there would be a significant buoy type effect $\left(P<0.0001, \mathrm{n}_{1}=\mathrm{n}_{2}=5, t\right.$-test $)$, whereby the swinging circle sediments of the hookbuoys displayed a lower density than the conventional buoys $(32,730$ compared with 70,840 ind. $\mathrm{m}^{-2}$ ).

Densities of single taxa

Figure 4 shows the abundance of single taxa in the sediment surface layers of the swinging circles, the undisturbed reference zones, as well as in the macrophyte stands of the reference sites.

Mussels (Bivalvia, BIV) and ostracods (Ostracoda, OST) were the most common forms, which had a mean density of over 10,000 ind. $\mathrm{m}^{-2}$. Young zebra mussels (Dreissena polymorpha Pall.) made up $96 \%$ of the mussel population and Pisidium species accounted for the remaining 4\%. Chironomid larvae (Dipt., Chironomidae, CHI), mayfly larvae (Ephemeroptera, EPH), oligochaetes (OLI), harpacticoida crustaceans (HAR), as well as snails (Gastropoda, GAS), also had high

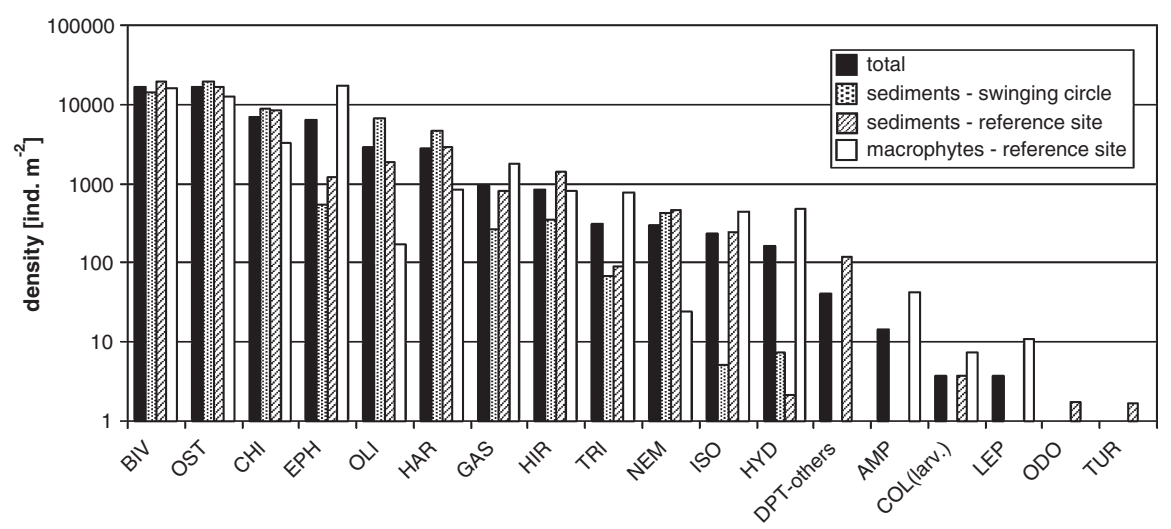

Fig 4 Distribution of mean densities of taxa in three substrates (for each: $n=12)$ as well as in the total data set $(n=36)$ (BIV-Bivalvia, OST-Ostracoda, CHI-Chironomidae (larvae), EPH-Ephemeroptera (larvae), OLI-Oligochaeta, HAR-Harpacticoidea, GAS-Gastropoda, HIR-Hirudinea,
TRI-Trichoptera (larvae), NEM-Nematoda, ISO-Isopoda, HYD-Hydrozoa, DPT-others-Diptera larvae other than Chironomidae, AMP-Amphipoda, COL-Coleoptera (larvae), LEP-Lepidoptera (larvae), ODO_Odonata (larvae), TUR-Turbellaria 
densities of an average between 1,000 and 10,000 ind. $\mathrm{m}^{-2}$. Among the chironomids, the sub-families Chironominae with $56 \%$, Tanypodinae with $28 \%$ and the Orthocladinae with $8 \%$ were represented, unidentifiable specimens accounted for the remainder. Among the mayflies, Caenis species with $73 \%$ were dominant, in comparison to Centroptilum sp. with only $4 \%$; a further $23 \%$ of the counted animals were young, non-classifiable larvae. Leeches (Hirudinea, HIR: Helobdella stagnalis L.-87\%, Erpobdella octoculata L. $-12 \%$, Glossiphona complanata L.-1\%), caddis fly larvae (Trichoptera, TRI: Mystacides sp.-81\%, Polycentropus sp.-2\%), roundworms (Nematoda, NEM), isopods (Isopoda, ISO: Asellus aquaticus (L.)) and hydrozoa (HYD) were present at much lower densities between 100 und 1,000 ind. $\mathrm{m}^{-2}$. It must be noted here however that the round worms and the hydrozoans were probably not quantitatively documented due to their small size and body shape. All further groups, including amphipods (Amphipoda, AMP), beetle larvae (Coleoptera, COL) and dragonfly larvae (Odonata, ODO) played no quantitative role.

The dominating groups were those which repeatedly occurred in all or almost all samples taken (Table 2, Frequency). When comparing the habitats it became apparent that individual groups showed differing preferences: hydrozoans, mayfly larvae, gastropods, isopods and Trichoptera larvae were found in significantly higher densities in the macrophyte stands than in the sediments. Chironomid larvae and oligochaetes in contrast were more common in the sediments (Table 2). Some taxa (BIV, GAS, HIR, ISO) were present in significantly higher densities on reference sediments than in the swinging circle sediments. In contrast to this, there were no taxa which were significantly more common in the swinging circle sediments. The buoy type had no significant influence on the pairwise difference of individual densities between swinging circle and reference site sediments. No influence of buoy type within the group of swinging circle sediments was noted: no taxonomical group showed significant differences in means of the individual densities in the sediments of conventional and hook-buoys.

\section{Community structure}

The composition of the macro-invertebrate assemblage in both the sediments and the macrophytes was dominated by ostracods, mussels, chironomid larvae and mayfly larvae, whereas oligochaete worms, harpacticoida crustaceans, snails and leeches were present to a lesser extent. All other taxa accounted for on average $2.3 \%$ of the total individual number.

Sediments and macrophyte stands exhibited differently composed macroinvertebrate assemblages. On the macrophytes the mayflies dominated, in comparison to ostracods, mussels and chironomid larvae. These latter taxa dominated in the sediments, whereas mayfly larvae played no role here. The percentage shares of many taxa differed significantly from one another according to habitat (Table 3). A phytophilous group, consisting of mayfly larvae, snails, caddis fly larvae, hydrozoans and isopods, can be distinguished from a psammophilous group of ostracods, chironomid larvae and oligochaetes.

A significant treatment effect could be seen in the composition of the assemblage (Table 3). The percentage of mussels, snails, leeches and isopods in the reference sites sediments was significantly higher than in the disturbed swinging circle sediments. However there was no taxon which was more common in the swinging circle sediments than in the reference sediments. There was no taxon which had a significantly different percentage share in the swinging circle sediments of conventional buoy sites than in the sediments of hook-buoy sites. The type of buoy therefore had no significant influence on the percentage composition of the macro-invertebrate assemblage.

Quantifying the effect of mooring on the total density of macro-invertebrates

The total density of macro-invertebrates of a reference site was equal to the sum of densities in the macrophyte stand and in the sediment below. The total density in a swinging circle was estimated to be equal to the density in the sediment when the small amount of macrophytes (see above) in the swinging circle was neglected. The relation between these two figures gives the total effect of mooring on macroinvertebrates. Table 4 shows that the mean density of phytophilous taxa was significantly higher in the reference sites than in the swinging circle, i.e. mooring reduced the mean density of all phytophilous taxa to $2 \%$ of the reference value. The density of 
Table 3 Comparison of the assemblage composition of the macro-invertebrates of the macrophyte stands $(n=12)$ and the sediments $(n=24)$ (habitat effect) as well as the swinging

\begin{tabular}{|c|c|c|c|c|c|c|}
\hline \multirow[t]{2}{*}{ Taxon } & \multicolumn{3}{|l|}{ Habitat effect } & \multicolumn{3}{|c|}{ Treatment effect (sediments) } \\
\hline & Macrophytes & Sediment & Sign. & Swinging circle & Reference site & Sign. \\
\hline Ostracoda & $23.1 \pm 12.1$ & $34.0 \pm 13.0$ & $*$ & & & \\
\hline Bivalvia & & & & $22.0 \pm 13.7$ & $35.4 \pm 17.4$ & * \\
\hline Chironomidae & $7.8 \pm 5.0$ & $17.6 \pm 12.3$ & * & & & \\
\hline Ephemeroptera & $33.6 \pm 20.0$ & $1.7 \pm 2.8$ & $* * * *$ & & & \\
\hline Oligochaeta & $0.4 \pm 0.6$ & $7.6 \pm 7.0$ & $* * * *$ & & & \\
\hline Gastropoda & $3.3 \pm 2.2$ & $1.2 \pm 2.4$ & $* *$ & $0.1 \pm 0.3$ & $1.5 \pm 1.9$ & $*$ \\
\hline Hirudinea & & & & $0.5 \pm 0.8$ & $2.7 \pm 3.5$ & $* *$ \\
\hline Trichoptera & $1.6 \pm 1.4$ & $0.2 \pm 0.2$ & $* * * *$ & & & \\
\hline Isopoda & $0.9 \pm 1.4$ & $0.2 \pm 0.8$ & $* * *$ & $0.0 \pm 0.0$ & $0.4 \pm 1.0$ & $* *$ \\
\hline Hydrozoa & $1.0 \pm 0.8$ & $0.0 \pm 0.0$ & $* * * *$ & & & \\
\hline
\end{tabular}

The means \pm SD (\% of all animals) as well as the significance of the Wilcoxon matched pairs signed rank test are all specified. Only taxa for which significant effects were found are displayed

For symbols see Table 1

Table 4 Comparison of macro-invertebrate density of reference sites (sediments + macrophytes, $n=12$ ) and swinging circles (sediments, $n=12$ ), means \pm SD of the $\log _{10}(\mathrm{Z}+1)$

\begin{tabular}{|c|c|c|c|c|}
\hline & Swinging circle & Reference site & Sign. & Swinging circle $\%$ of the reference \\
\hline Hydrozoa & $0.57 \pm 0.62$ & $2.54 \pm 0.44$ & $* * * *$ & 1 \\
\hline Ephemeroptera & $2.12 \pm 0.72$ & $4.17 \pm 0.33$ & $* * * *$ & 1 \\
\hline Gastropoda & $1.26 \pm 1.12$ & $3.20 \pm 0.57$ & $* * * *$ & 1 \\
\hline Isopoda & $0.29 \pm 0.57$ & $2.43 \pm 0.79$ & $* * * *$ & 1 \\
\hline Trichoptera & $1.70 \pm 0.36$ & $2.80 \pm 0.37$ & $* * * *$ & 8 \\
\hline Sum of phytophilous taxa & $2.60 \pm 0.59$ & $4.29 \pm 0.28$ & $* * * *$ & 2 \\
\hline Chironomidae & $3.81 \pm 0.37$ & $4.01 \pm 0.23$ & n.s. & 64 \\
\hline Oligochaeta & $3.62 \pm 0.57$ & $2.91 \pm 0.68$ & $*$ & 515 \\
\hline Ostracoda & $4.20 \pm 0.33$ & $4.41 \pm 0.24$ & n.s. & 61 \\
\hline Sum of psammophilous taxa & $4.50 \pm 0.20$ & $4.59 \pm 0.21$ & n.s. & 81 \\
\hline Total & $4.69 \pm 0.23$ & $5.00 \pm 0.19$ & $* *$ & 49 \\
\hline
\end{tabular}

For symbols see Table 1

psammophilous taxa was not significantly reduced, since their density on macrophytes was much lower than in sediments. Interestingly, the oligochaetes were strongly stimulated by the mooring, and in the bare sediments of swinging circles their mean density was 5-fold higher than in the reference sites. The mean total density of all macro-invertebrate taxa was halved by the dredging of the anchor chain in the swinging circles (Table 4). circle sediments $(n=12)$ and the reference area sediments $(n=12)$ (treatment effect) 
swinging circle for reasons of operational safety. The required area in the Gundholzen buoy field was $580 \mathrm{~m}^{2}$ for conventional buoys (space between the anchor stones of the buoys approx. $23 \mathrm{~m}$ ) and $387 \mathrm{~m}^{2}$ for hook-buoys (approx. $18 \mathrm{~m}$ ). Basically, in a 1 hectare mooring area only about 17 boats could be moored using conventional buoys, whereas about 26 boats could be moored using hook-buoys, i.e. about $50 \%$ more. Table 5 compares the overall effects on the phytomass, some sediment properties, and the densities of macro-invertebrates on the basis of four scenarios:

Table 5 Overview of the overall effects of scenarios 2, 3 and 4, in comparison to scenario 1 (area left in its natural state without a mooring) with reference to the average mooring area of $580 \mathrm{~m}^{2}$ (see text for details)

\begin{tabular}{|c|c|c|c|c|}
\hline & Scenario 1 & Scenario 2 & Scenario 3 & Scenario 4 \\
\hline Treatment & Natural & Conventional buoy & Hook-buoy & Hook-buoy \\
\hline Reference area $\left(\mathrm{m}^{2}\right)$ & 580 & 580 & 580 & 580 \\
\hline Mooring area per boat $\left(\mathrm{m}^{2}\right)$ & 0 & 580 & 580 & 387 \\
\hline No. of boats (1) & 0 & 1 & 1 & 1.5 \\
\hline \multicolumn{5}{|l|}{ Swinging circle area } \\
\hline$\%$ of scenario 1 & 0 & $15.0 \pm 6.4$ & $1.0 \pm 0.8$ & $1.5 \pm 1.2$ \\
\hline \multicolumn{5}{|l|}{ Eroded fine sediment matter } \\
\hline$(<0.112$ mm) kg d.m. & 0 & $907 \pm 940$ & $20 \pm 28$ & $31 \pm 42$ \\
\hline$\%$ of scenario 1 & 0 & $17.5 \pm 18.5$ & $0.4 \pm 0.6$ & $0.6 \pm 0.9$ \\
\hline \multicolumn{5}{|l|}{ Organic matter $(\mathrm{OM})$, sediment } \\
\hline $\mathrm{kg}$ in the ref. area & 241.6 & & & \\
\hline$\%$ of scenario 1 & 100 & $95.5 \pm 7.1^{\text {n.s. }}$ & $99.9 \pm 0.3^{\text {n.s. }}$ & $99.8 \pm 0.5^{\text {n.s. }}$ \\
\hline \multicolumn{5}{|l|}{ Total phosphorus $\left(\mathrm{P}_{\mathrm{t}}\right)$, sediment } \\
\hline $\mathrm{kg}$ in the ref. area & 2.38 & & & \\
\hline$\%$ of scenario 1 & 100 & $108.0 \pm 5.4^{*}$ & $100.0 \pm 0.2^{\text {n.s. }}$ & $100.0 \pm 0.5^{\text {n.s. }}$ \\
\hline \multicolumn{5}{|l|}{ Vegetation free area } \\
\hline $\mathrm{m}^{2}$ in the ref. area & $51 \pm 25$ & & & \\
\hline$\%$ of scenario 1 & 100 & $222 \pm 69^{* *}$ & $115 \pm 15^{*}$ & $122 \pm 22 *$ \\
\hline \multicolumn{5}{|l|}{ Phytomass } \\
\hline $\mathrm{kg} \mathrm{OM}$ in the ref. area & $90 \pm 28$ & & & \\
\hline$\%$ of scenario 1 & 100 & $85.4 \pm 6.7 * *$ & $99.1 \pm 0.8^{*}$ & $98.6 \pm 1.2 *$ \\
\hline \multicolumn{5}{|l|}{ Macro-invertebrates } \\
\hline ind. in the ref. area & $62.9 \pm 27.6 \times 10^{6}$ & & & \\
\hline$\%$ of scenario 1 & 100 & $95.2 \pm 7.7^{\text {n.s. }}$ & $99.6 \pm 0.3^{\text {n.s. }}$ & $99.4 \pm 0.5^{\text {n.s. }}$ \\
\hline $\begin{array}{l}\text { Psammophilous macro-invert } \\
\text { ind. in the ref. area }\end{array}$ & $25.1 \pm 11.8 \times 10^{6}$ & & & \\
\hline$\%$ of scenario 1 & 100 & $97.0 \pm 7.8^{\text {n.s. }}$ & $100.2 \pm 0.3^{\text {n.s. }}$ & $100.3 \pm 0.4^{\text {n.s. }}$ \\
\hline \multicolumn{5}{|c|}{ Phytophilous macro-invertebrates } \\
\hline ind. in the ref. area & $13.4 \pm 6.8 \times 10^{6}$ & & & \\
\hline$\%$ of scenario 1 & 100 & $87.3 \pm 4.6^{* *}$ & $99.1 \pm 0.8^{*}$ & $98.7 \pm 1.2^{*}$ \\
\hline \multicolumn{5}{|l|}{ Mayfly larvae (EPH) } \\
\hline ind. in the ref. area & $10.7 \pm 6.1 \times 10^{6}$ & & & \\
\hline$\%$ of scenario 1 & 100 & $87.8 \pm 4.4^{* *}$ & $99.1 \pm 0.8^{*}$ & $98.6 \pm 1.2^{*}$ \\
\hline
\end{tabular}

The absolute means \pm SD are displayed for $n=12$ areas of scenario 1, the percentage means \pm standard deviations for every $n=6$ area of Scenarios 2-4, as well as the statistical test results (two tailed $t$-test [scenario 2] and the Wilcoxon matched pairs signed rank test [scenarios 3 and 4]

For symbols see Table 1 
Scenario 1 is the basic scenario which reflects the natural conditions without any berths. In scenario 2 (conventional buoys) an average of $15 \%$ of the total mooring area is disturbed by the swinging circle. The vegetation free area was therefore about $120 \%$ higher than in natural areas; the total phytomass decreased by about $15 \%$. The quantities of organic matter in the sediment surface layer decreased by c. 5\% whereas $\mathrm{P}_{\mathrm{t}}$ increased by $8 \%$. The total number of macroinvertebrate organisms in the sediment surface layer and in the macrophyte stands was by 5\% lower. The psammophilous macroinvertebrates (OST + OLI + $\mathrm{CHI}$ ), which had slightly higher densities in the swinging circle sediments than in the sediments covered with macrophytes (Fig. 4), reacted positively to the disturbance, so that the individual numbers of this group increased slightly. The phytophilous macroinvertebrates (HYD + EPH + GAS + ISO + TRI) reacted negatively, which was due to the decrease of macrophyte cover in the swinging circle by $13 \%$. This also applied to the most affected taxonomic group, the mayfly larvae.

In comparison, the impacts of the hook-buoys were less (scenario 3), mainly due to the fact that the swinging circle was smaller. The swinging circle only encompassed $1 \%$ of the reference area, the vegetation free area increased by $15 \%$, the phytomass was reduced by about $1 \%$. The quantity of OM was only $0.1 \%$ lower, and the $\mathrm{P}_{\mathrm{t}}$ amount remained nearly unchanged. The total number of macro-invertebrates as well as the individual numbers of the above named groups only differed by less than $1 \%$ from the natural condition (scenario 1).

In scenario 1 there was no erosion by definition. In scenario 2 the eroded fine sediment amounted to $907 \mathrm{~kg}$ per mooring site on average which was $17.5 \%$ of the total amount of fine matter in the mooring site sediments $(0-3 \mathrm{~cm}$ depth). The eroded matter was much lower in scenario 3 due to the smaller swinging circle and the lower sediment loss per square meter.

Generally, scenario 4, which in comparison to scenario 3 increases the mooring density from 1 to 1.5 boats every $580 \mathrm{~m}^{2}$, aggravated the effects shown for scenario 3. Even in this case, the overall effects were far lower than those of conventional buoys. The effect of the increase in the number of anchor stones was neglected because the anchor stone area made up only $0.1-0.2 \%$ of the total area of a mooring site.

\section{Discussion}

In this study we investigated the effects of two similar types of buoy moorings in Lake Constance on sediments, submerged vegetation and macro-invertebrate fauna against the background of a natural site free from moored boats. In buoy mooring systems boats are held in place by the gravity of a heavy anchor chain fixed to the anchor stone (Figs. 1, 2). With fluctuating water level and changing wind, the anchor chain drags along the ground around the central anchor stone, forming a circular swinging zone. On soft ground, the chain penetrates the uppermost sediment layer which is ploughed through. The frequency of such disruption is not known, but is estimated in the range of days up to a week to complete a circle. Some sectors may be more frequently affected than others, depending on the direction and the strength of prevailing winds. Field observations showed that only a moderate breeze is necessary to move the boat and to let the anchor chain swing. The submerged plants, in this case dense Chara beds, are uprooted and washed away. Thereby, the mean vegetation cover and the phytomass per unit area are strongly reduced in the swinging circle, and the mean plant species number per plot decreases (Table 1).

The dragging of the anchor chain leads to a suspension of surficial sediment matter into the water column. Larger grains may settle down within a few seconds, finer grains are carried away by littoral currents which are strongest during stiff breeze and storm. We found that the grain size fraction $>0.200 \mathrm{~mm}$ remains more or less unaffected but the fraction $<0.112$ has been reduced by $27 \%$ on average in the uppermost $3 \mathrm{~cm}$ sediment layer in the swinging circle. Accordingly, sediment components which are bound to the finer fraction, are also significantly reduced, e.g. the content of organic matter (reduction of $45 \%$ ) and biogenic carbonates ('lake marl', reduction of $38 \%$ ). The total phosphorus content, however, was not significantly affected.

We investigated the density and the community structure of macro-invertebrates $(>0.2 \mathrm{~mm}$ mesh size) in the unaffected sediments and in the Chara beds of the reference sites, and in the disturbed sediments of the swinging circles. The mean total densities in the reference sites were nearly the same in the Chara stands $\left(48,750\right.$ individuals $\left.\mathrm{m}^{-2}\right)$ and in 
the corresponding sediments $\left(48,860\right.$ ind. $\mathrm{m}^{-2}$ in the $0-3 \mathrm{~cm}$ layer). This is in contrast with many findings in the literature, according to which the macro-invertebrate density is normally much higher in macrophyte stands than in the sediments (Gerking 1957; Pieczynski 1973; Soszka 1975; Vincent et al. 1982; Rasmussen 1988).

The community structure in the reference sites was dominated by ostracods, mussels (mainly Dreissena polymorpha), chironomid larvae and mayfly larvae which have been proved to be among the most frequent taxonomic groups in many other lentic lake shore habitats. However, the abundance of oligochaetes was lower than expected. Large-sized invertebrates like amphipods, bugs, and larvae of beetles, butterflies and dragonflies were nearly absent, presumably due to the high predation pressure of fish (Laughlin and Werner 1980; Crowder and Cooper 1982; Gilinsky 1984; Mittelbach 1984; Keast 1985; Diehl 1992; Tolonen et al. 2001) or waterfowl (Krull 1970; Danell and Sjöberg 1980; Murkin and Kadlec 1986).

Mayfly larvae, snails, caddis fly larvae, hydrozoans and isopods (phytophilous taxa) were significantly more abundant in the Chara vegetation than in the underlying sediments, whereas ostracods, chironomid larvae and oligochaetes were more abundant in the sediment (psammophilous taxa). It is generally accepted that most benthic taxa have some degree of preference for a certain substrate, so that characteristic macroinvertebrate assemblages can be found for each substrate type (Minshall 1984; Ward 1992; Hoffmann et al. 1996; Giller and Malmqvist 1999; Heino 2000), though many taxa live on, and move between both substrates (Keast 1984; Rabe and Gibson 1984; Rasmussen 1982, 1988).

While destroying the submerged vegetation, the swinging anchor chain also destroys potential habitats for invertebrates. Hence, the total density of macroinvertebrates is reduced by $51 \%$ compared with the reference (sediment + macrophytes) (Table 4). All phytophilous taxa are significantly affected (reduction of 98\%) whereas some psammophilous taxa are not significantly affected or significantly increase their density (oligochaetes: 5-fold increase).

Anchor chain action also modifies the stability and the physical properties of the surficial sediments as shown above. This lead to significantly lower densities of mussels, snails, leeches and isopods (Table 2) in the swinging circle sediments compared to the sediments of the reference sites, and to increases of ostracods, oligochaetes and harpacticoidea densities, which were, however, not significant (Fig. 4). The mean total density of macro-invertebrates remained virtually unchanged. We propose that the modification of the taxonomic composition of the swinging circle sediment fauna is predominantly the result of the frequent and steady disturbance by the dragging anchor chain but the changed physical properties (sediment coarsening, lower content of fine organic particles) may also play an important role. When the anchor chain ploughs through the sediment, small and mobile animals (e.g. isopods) may be suspended to the water column, and are then washed away or subjected to high predation by fish. Sedentary life forms may be subjected to higher mortality by ploughing due to anchor chain action and sediment cover (e.g. snails, leeches).

In this investigation two types of buoy management were compared. The conventional buoy management gives rise to swinging circles which are 14.5 times larger in area than the swinging circles of the hook-buoy system. Means of vegetation cover, sediment properties (bulk density, organic matter, total phosphorus, total carbonate, grain-size distribution), density of macro-invertebrate taxa and community composition in the swinging circle did not show any significant effect of buoy type. However, the total density of macro-invertebrates was significantly lower in the hook-buoy system if two outliers were eliminated from the data set. Potentially, the percentage area affected by the anchor chain movement was higher in this narrow swinging circle than in the much wider disturbance zone of the conventional buoys. For all other parameters the consequences of hook-buoys are mainly size effects of the swinging circle area.

The final goal of this study was to identify possible harmful effects of mooring sites to lake littoral habitats, and to give details to managers for a future mooring management with the least ecological impacts. Based on the results from our investigations we designed four scenarios. Scenario 1 reflected a completely natural littoral area with no moorings. The other scenarios represented the two mooring types with different densities of anchored boats (Table 5). The conventional buoy moorings (scenario 2) had strong effects on sediment matter erosion, total phosphorus, vegetation free area, phytomass of 
submerged vegetation, and the density of phytophilous macro-invertebrates, especially on mayfly larvae, compared with scenario 1 . The relative impact exceeded $10 \%$ of the reference, e.g. the vegetation free area was more than doubled, and the number of mayfly larvae was reduced by $12 \%$. The hook-buoy system (scenarios 3 and 4) caused much lower disturbance, so that the relative impact did not exceed $1 \%$ of the reference, when the number of boats remained unchanged (scenario 3), and did not exceed $2 \%$, when the number of boats increased by $50 \%$. Only the vegetation free area increased by $15 \%$, and $22 \%$, respectively. The minor ecological effects of the hook-buoy system are mainly due to the much smaller swinging circle of the anchor chain.

Our results can be generalised for other buoy fields of Lake Constance since (i) the common littoral floor consists of soft sediments which are covered with Chara and Potamogeton vegetation, (ii) all littoral sections are more or less affected by winds from varying directions, (iii) modalities of installation and use of buoy fields (e.g. water depth, boat size, conventional mooring system) are essentially the same. Presumably, the effects for exposed buoy fields may be even greater than in the sheltered Gundholzen buoy field because longer and/or heavier anchor chains could be necessary for reasons of operational safety. They cause larger swinging circles, deeper ploughing and a higher frequency of chain movement. The result may be generalised for other lakes, provided that there is a vegetated soft-bottom littoral and some wind and wave action so that the boats swing.

The impact on sediments, vegetation and macroinvertebrates may have consequences for juvenile and adult fish (Crowder and Cooper 1982; Hanson and Legett, 1982; Mittelbach 1984; Keast 1985), and waterfowl (Szijj 1965; van Donk et al. 1994; Søndergaard et al. 1996; Schmieder et al. 2006) which feed on macro-invertebrates or on Chara stands together with their epifauna. However, functional chains are complex, and include the structuring role of swinging circles, the shading by boats, the disturbance frequency by yachtsman, as well as behavioural patterns of the species in question. Whether the direct or indirect effects are significant for the whole lake ecosystem depends also on the ratio of littoral to open water surface, the share of littoral area which is occupied by buoy fields, the density of mooring sites, and the size of boats. These basic factors may vary strongly among lakes, according to their function as a water sports amenity. On Lake Constance the impact of buoy fields seems to be limited since $85.3 \%$ of all berths are concentrated in harbours and landing stages. Albeit, the policy of competent authorities is to reduce the impact of buoy fields because large littoral areas are NATURA 2000 habitats which are protected by the European Habitats Directive. According to our results, the way to do this under the premise of constant boat numbers is (i) to replace the space-consuming conventional mooring system by the space-saving hook-buoy system (or another comparable mooring system), and (ii) to reduce the total area of buoy fields by concentrating 1.5 boats on hook-buoys in 1 berth formerly operated conventionally (scenario 4, Table 5).

The results of this study have shown that spaceconsuming mooring system have detrimental effects on sediments, submerged vegetation, and density and composition of the macro-invertebrate fauna. It is, however, possible to install simple and inexpensive mooring devices (e.g. the hook-buoy system) which aid in reducing the degree of disturbance.

Acknowledgements We wish to thank Christof Stier for his assistance during field sampling, Marc Hamitou for enumeration and determination of difficult taxa, two anonymous reviewers for helpful comments, and Rachel Kemp for linguistic corrections. We are also indebted to Martin Wessels at the Institute for Lake Research, Langenargen for making the grain size analyses. The study was partly funded by the Plenum Westlicher Bodensee programme.

\section{References}

Armitage PD, Pardo I, Brown A (1995) Temporal constancy of faunal assemblages in "mesohabitats" application to management? Arch Hydrobiol 133:367-387

Bäuerle E, Ollinger D, Ilmberger J (1998) Some meteorological, hydrological, and hydrodynamical aspects of Upper Lake Constance. Arch Hydrobiol Spec Issues Advanc Limnol 53:31-83

Buttler KP, Harms K (1998) Florenliste von Baden-Wüerttemberg. Liste der Farn- und Samenpflanzen (Pteridophyta et Spermatophyta). Naturschutz-Praxis, Artenschutz, vol 1. Stuttgart, $486 \mathrm{pp}$

Creed JC, Amado Filho GM (1999) Disturbance and recovery of the macroflora of a seagrass (Halodule wrightii Ascherson) meadow in the Abrolhos Marine National Park, Brazil: an experimental evaluation of anchor damage. J Exp Mar Biol Ecol 235:285-306. doi:10.1016/S00220981(98)00188-9 
Crowder LB, Cooper WE (1982) Habitat structural complexity and the interaction between bluegill and their prey. Ecology 63:1802-1813. doi:10.2307/1940122

Danell K, Sjöberg K (1980) Foods of wigeon, teal, mallard and pintail during summer in a northern Swedish lake. Swed Wildl Res Viltrevy 11:141-167

Diehl S (1992) Fish predation and benthic community structure:the role of omnivory and habitat complexity. Ecology 73:1646-1661. doi:10.2307/1940017

Francour P, Ganteaume A, Poulain M (1999) Effects of boat anchoring in Posidonia oceanica seagrass beds in the Port-Cros National Park (north-western Mediterranean Sea). Aquat Conserv 9:391-400. doi:10.1002/(SICI) 10990755(199907/08)9:4<391::AID-AQC356>3.0.CO;2-8

Gerking SD (1957) A method of sampling the littoral macrofauna and its application. Ecology 38:219-226. doi:10. $2307 / 1931680$

Gilinsky E (1984) The role of fish predation and spatial heterogeneity in determining benthic community structure. Ecology 65:455-468. doi:10.2307/1941408

Giller PS, Malmqvist B (1999) The biology of streams and rivers. Oxford University Press, Avon, 296 pp

Hanson JM, Legett WC (1982) Empirical prediction of fish biomass and yield. Can J Fish Aquat Sci 39:257-263. doi: 10.1139/f82-036

Hastings K, Hesp P, Kendrick G (1995) Seagrass loss associated with boat moorings at Rottnest Island, Western Australia. Ocean Coast Manage 26:225-246. doi:10.1016/ 0964-5691(95)00012-Q

Heino J (2000) Lentic macroinvertebrate assemblage structure along gradients in spatial heterogeneity, habitats size and water chemistry. Hydrobiologia 418:229-242. doi:10.1023/A:1003969217686

Hoffmann RL, Liss WJ, Larson GL, Deimling EK, Lomnicky GA (1996) Distribution of nearshore macroinvertebrates in lakes of the Northern Cascade Mountains, Washington, USA. Arch Hydrobiol 136:363-389

IGKB (Internationale Gewässerschutzkommission für den Bodensee) (2005) Auswertung der Statistik der Schifffahrtsanlagen für 2003. http://www.igkb.de

Keast A (1984) The introduced aquatic macrophyte, Myriophyllum spicatum, as habitat for fish and their invertebrate prey. Can J Zool 62:1289-1303

Keast A (1985) Planktivory in a littoral-dwelling fish association, prey selection and seasonality. Can J Fish Aquat Sci 42:1114-1126

Krause W (1997) Charales (Charophyceae). In: Süesswasserflora von Mitteleuropa, vol 18. Fischer, Jena, 202 pp

Krull JN (1970) Aquatic plant-macroinvertebrate associations and waterfowl. J Wildl Manage 34:707-718. doi:10.2307/ 3799135

Laughlin DR, Werner EE (1980) Resource partitioning in two coexisting sunfish: pumpkinseed (Lepomis gibbosus) and northern longear sunfish (Lepomis magalotis peltastes). Can J Fish Aquat Sci 37:1411-1420

Lenihan HS, Oliver JS, Stephenson MA (1990) Changes in hard bottom communities related to boat mooring and tributyltin in San Diego Bay California USA: a natural experiment. Mar Ecol Prog Ser 60:147-160. doi:10.3354/ meps060147
Marba N, Duarte C, Holmer M, Martinez R, Basterretxea G, Orfila A, Jordi A, Tintore J (2002) Effectiveness of protection of seagrass (Posidonia oceanica) populations in Cabrera National Park (Spain). Environ Conserv 29:509518. doi:10.1017/S037689290200036X

Milazzo M, Badalamenti F, Ceccherelli G, Chemello R (2004) Boat anchoring on Posidonia oceanica beds in a marine protected area (Italy, western Mediterranean): effect of anchor types in different anchoring stages. J Exp Mar Biol Ecol 299:51-62. doi:10.1016/j.jembe.2003.09.003

Minshall GW (1984) Aquatic insect-substratum relationships. In: Resh VH, Rosenberg DM (eds) The ecology of aquatic insects. Praeger, NY, pp 358-400

Mittelbach GG (1984) Predation and resource partitioning in two sunfishes (Centrarchidae). Ecology 65:499-513. doi: $10.2307 / 1941412$

Murkin HR, Kadlec JA (1986) Relationships between water fowl and macroinvertebrate densities in a northern prairie marsh. J Wildl Manage 50:212-217. doi:10.2307/ 3801899

Pieczynski E (1973) Experimentally increased fish stock in the pond type Lake Warniak XII Numbers and biomass of the fauna associated with macrophytes. Ekol Pol A 11: 533-545

Rabe FW, Gibson F (1984) The effect of macrophyte removal on the distribution of selected invertebrates in a littoral environment. J Freshwat Ecol 2:359-371

Rasmussen JB (1982) The influence of thermal effluent, before and after macrophyte harvesting, on standing crop and species composition of benthic macroinvertebrate communities in Lake Wabamun, Alberta. Can J Zool 60: 3196-3205. doi:10.1139/z82-405

Rasmussen JB (1988) Littoral zoobenthic biomass in lakes, and its relationship to physical, chemical, and trophic factors. Can J Fish Aquat Sci 45:1436-1447

Schmieder K, Werner S, Bauer H-G (2006) Submersed macrophytes as a food source für wintering waterbirds at Lake Constance. Aquat Bot 84:245-250. doi:10.1016/ j.aquabot.2005.09.006

Søndergaard M, Bruun L, Lauridsen T, Jeppesen E, Madsen TV (1996) The impact of grazing waterfowl on submerged macrophytes: in situ experiments in a shallow eutrophic lake. Aquat Bot 53:73-84. doi:10.1016/03043770(95)01013-0

Soszka GJ (1975) The invertebrates on submerged macrophytes in three Masurian lakes. Ekol Polska 23:371-391

Szijj J (1965) Ökologische Untersuchungen an Entenvögeln (Anatidae) des Ermatinger Beckens (Bodensee). Vogelwarte 23:24-70

Tolonen KT, Hämaläinen H, Holopainen IJ, Karjalainen J (2001) Influences of habitat type and environmental variables on littoral macroinvertebrate communities in a large lake system. Arch Hydrobiol 152:39-67

van Donk E, De Deckere E, Klein-Breteler JGP, Meulemanns JT (1994) Herbivory by waterfowl and fish on macrophytes in a biomanipulated lake: effects on long-term recovery. Verh Int Ver Limnol 25:2139-2143

Vincent B, Lafontaine N, Caron P (1982) Facteurs influençant la structure de groupement de macro-invertébrés benthiques et phytophiles dans la zone littorale du Saint-Laurent 
(Québec). Hydrobiologia 97:67-73. doi:10.1007/BF0001 4959

Wade PM (1999) The impact of human activity on the aquatic macroflora of Llangorse Lake, South Wales. Aquat Conserv 9:441-459. doi:10.1002/(SICI)1099-0755(199909/ 10)9:5<441::AID-AQC359>3.0.CO;2-J
Walker DI, Lukatelich RJ, Bastyan G, McComb AJ (1989) Effect of boat moorings on seagrass beds near Perth Western Australia. Aquat Bot 36:69-78. doi:10.1016/ 0304-3770(89)90092-2

Ward JV (1992) Aquatic insect ecology: 1 Biology and habitat. Wiley, New York, 438 pp 